\title{
Effect of postsurgical chronic hypoparathyroidism on morbidity and mortality: a systematic review and meta-analysis
}

\author{
Deena Hadedeya ${ }^{1}$, Joshua Kay ${ }^{2}$, Abdallah Attia ${ }^{1}$, Mahmoud Omar $^{1} \wedge$, Mahmoud Shalaby ${ }^{1}$, Mohanad R. Youssef ${ }^{1}$, \\ Mohamed Shama ${ }^{1}$, Eman Toraih $^{1,3}$, Emad Kandil $^{1}$ \\ ${ }^{1}$ Department of Surgery, Tulane University School of Medicine, New Orleans, LA, USA; ${ }^{2}$ Department of Otolaryngology, Tulane University School \\ of Medicine, New Orleans, LA, USA; ${ }^{3}$ Genetic Unit, Department of Histology and Cell Biology, Faculty of Medicine, Suez Canal University, \\ Ismailia, Egypt \\ Contributions: (I) Conception and design: D Hadedeya, E Kandil; (II) Administrative support: D Hadedeya, A Attia, M Omar; (III) Provision of study \\ materials or patients: D Hadedeya, J Kay, A Attia, M Omar, M Shalaby, MR Youssef; (IV) Collection and assembly of data: D Hadedeya, M Shalaby; (V) \\ Data analysis and interpretation: E Toraih; (VI) Manuscript writing: All authors; (VII) Final approval of manuscript: All authors. \\ Correspondence to: Emad Kandil, MD, MBA, FACS. Tulane School of Medicine, Department of Surgery, 1430 Tulane Ave, SL-22, New Orleans, LA \\ 70112, USA. Email: ekandil@tulane.edu.
}

Background: Hypoparathyroidism (HypoPT) is a common sequela of anterior neck surgeries. While the
acute risks of HypoPT are well known, emerging evidence is beginning to define the risks chronic HypoPT
poses to patients. This meta-analysis aims to evaluate that risk and give more insight into its consequences.
Methods: A systematic review and meta-analysis were performed, searching EMBASE, Web of Science,
and Scopus for studies published up to July 1, 2020 and reported following PRISMA guidelines. Pooled
analysis was estimated using the Mantel-Haenszel method and a random-effects model. A sub-analysis of the
pooled data for each morbidity was performed and demonstrated in forest plots. Results: Patients with postsurgical chronic HypoPT had a high risk of cardiac morbidities [odds ratio (OR) $=1.43 ; 95 \%$ confidence interval $(95 \% \mathrm{CI}): 1.21$ to $1.70 ; \mathrm{P}<0.001]$ in the absence of elevated risk of cardiac arrhythmias (OR $=1.35,95 \% \mathrm{CI}: 0.96$ to $1.79, \mathrm{P}=0.08)$. Analysis also showed higher odds of developing renal disease ( $\mathrm{OR}=4.85,95 \% \mathrm{CI}: 3.54$ to $6.67, \mathrm{P}<0.001)$, renal stones $(\mathrm{OR}=3.86,95 \% \mathrm{CI}: 1.81$ to $8.23, \mathrm{P}<0.001)$, seizures $(\mathrm{OR}=2.41,95 \% \mathrm{CI}: 1.66$ to $3.5, \mathrm{P}<0.001)$, mental health problems (OR =1.46, 95\% CI: 1.21 to 1.77 , $\mathrm{P}<0.001$ ), and infections ( $\mathrm{OR}=1.51,95 \% \mathrm{CI}: 1.28$ to $1.78, \mathrm{P}<0.001)$. Conversely, HypoPT has no effect on mortality risk (OR $=1.19,95 \% \mathrm{CI}: 0.96$ to $1.49, \mathrm{P}=0.12$ ).

Conclusions: Postsurgical HypoPT patients are vulnerable to a variety of medical and psychiatric diseases. This meta-analysis should guide surgeons in preoperative counseling and postoperative care for patients undergoing anterior neck surgeries.

Keywords: Hypoparathyroidism (HypoPT); morbidity; mortality; chronic hypoparathyroidism; meta-analysis

Submitted Mar 20, 2021. Accepted for publication Aug 25, 2021.

doi: 10.21037 /gs-21-181

View this article at: https://dx.doi.org/10.21037/gs-21-181

\section{Introduction}

Chronic hypoparathyroidism is a rare endocrine disorder which can be transient or permanent. Hypoparathyroidism (НypoPT) has an incidence of $24-40$ per 100,000 in the United States and Europe, with a lower prevalence $(10.1$ per 100,000$)$ in Norway $(1-8)$. The most common cause of chronic HypoPT is parathyroidectomy or accidental removal of parathyroid glands during thyroid

^ ORCID: 0000-0001-7917-7973. 
Table 1 Electronic search criteria for systematic review for postsurgical chronic hypoparathyroidism

\begin{tabular}{|c|c|c|}
\hline Database & Search criteria & Citations \\
\hline Web of Science & $\begin{array}{l}\text { TS=(('hypoparathyroidism') AND ('mortality' OR 'morbidity' OR 'cardiovascular disease' OR 'heart disease' } \\
\text { OR 'cardiac complications' OR 'cardiovascular' OR 'heart' OR 'renal' OR 'renal complications' OR } \\
\text { 'complications' or 'death')) }\end{array}$ & 2,029 \\
\hline
\end{tabular}

Table 2 PICOS criteria for the systematic search

\begin{tabular}{lll}
\hline Parameters & Inclusion criteria & Exclusion criteria \\
\hline Population & Males and non-pregnant females $>18$ years old & Prior chronic kidney disease \\
Intervention/exposure & Diagnosis of hypoparathyroidism & - \\
Comparator & Normal parathyroid function & - \\
Outcome & Development of a comorbid condition or mortality & - \\
Study design & Case-control, cohort studies, and randomized & Case reports, commentary, non-English studies, book \\
& controlled trials & chapters, pilot studies, literature reviews, articles without \\
& & full text available
\end{tabular}

PICOS, Population, Intervention, Comparator, Outcome, and Study Design.

surgery $(1-5,8)$. Postsurgical HypoPT was estimated at 6.4-29 per 100,000 , compared to $2.3-17$ per 100,000 in non-surgical patients $(1-5,8)$. Chronic HypoPT is defined as the use of vitamin D or calcium supplements for more than six months to maintain normocalcemia (9). The incidence rate of postsurgical HypoPT ranges from $1.17 \%$ to $12.1 \%$ in some reports (10-13).

Little data is available on the effect of postsurgical chronic HypoPT on morbidity and mortality. Several studies with small sample sizes have reported the effects of HypoPT on cardiovascular, renal, and cerebrovascular systems. The same reports have described chronic HypoPT as a potential cause of fracture, cataract, malignancy, infection, psychiatric disorders, and death $(2,3,14-18)$. To our knowledge, this is the first meta-analysis to evaluate the impact of chronic HypoPT on developing morbidities and mortality. We present the following article in accordance with the PRISMA reporting checklist (available at https:// dx.doi.org/10.21037/gs-21-181).

\section{Methods}

\section{Literature search}

A comprehensive web-based literature search was performed on the EMBASE, Web of Science, and Scopus databases for articles published up to July 1, 2020, using a widespread literature screening. The primary objective was to determine the risk of developing morbidities and mortality among patients with postsurgical chronic HypoPT. The search algorithm included all occurrences in the title or abstract of the terms: "hypoparathyroidism" and "mortality" or "morbidity" or "cardiovascular disease" or "heart disease" or "cardiac complications" or "cardiovascular" or "heart" or "renal" or "renal complications" or "complications" or "death." Exact search terms are shown in Table 1. Inclusion criteria were defined using the Population, Intervention, Comparator, Outcome, and Study Design (PICOS) approach (Table 2). Males and non-pregnant females over the age of 18 diagnosed with 
postsurgical chronic HypoPT without prior renal disease were compared to those without postsurgical chronic HypoPT. The outcomes of interest were the development of any comorbid condition or mortality. The study designs included randomized controlled trials (RCT), case-control studies, and cohort studies. We excluded case reports, commentary, non-English articles, book chapters, pilot studies, and literature reviews from the study. Conference proceedings and unpublished studies were included if they provided sufficient information, including demographics and outcomes. The Preferred Report Items for Systematic Reviews and Meta-Analyses (PRISMA) standards were used to ensure adequate reporting of this meta-analysis (19).

\section{Data extraction and selection}

All included citations were extracted and compiled into a citation management software (Endnote X9.2) by title, author, journal, year of publication, and article type. Duplicate articles were removed. A manual review of the articles was performed independently by two coinvestigators (DH and MS). Articles were screened in two stages. First, articles were manually screened for inclusion by title/abstract, followed by full-text review for exclusion. For potentially repetitive data presented in two separate publications by a single institution, the more recent publication was included. Bibliographies of the selected articles were reviewed to ensure the inclusion of all relevant literature. No data was repeated or shared between selected articles. All disputes over inclusion or exclusion were first discussed among two authors (DH, MS). Any unresolved discrepancy was then solved by the corresponding investigator (EK).

We extracted data from the relevant articles, including demographics, type of morbidity, and mortality. Frequency data were collected as fractions of exposures over outcomes. Relative risk and odds ratios were collected with calculations for validity, such as confidence intervals and $\mathrm{P}$ values. Data for morbidities were further divided into subgroups based on disease process: (I) cardiovascular, (II) renal, (III) neuropsychiatric, (IV) immunologic and oncologic, (V) skeletal, and (VI) ophthalmic. Risk of mortality was also assessed.

\section{Cases and control population}

Cases were identified as patients who needed vitamin D or calcium supplements for more than 6 months to maintain normocalcemia following thyroidectomy or parathyroidectomy. The control group included the following: (I) normal population, (II) patients who developed non-surgical hypoparathyroidism, and (III) postsurgical patients with preserved parathyroid function.

\section{Quality assessment}

Quality was assessed at the study level by evaluating the authors' stated purpose, study design, and source of data collection for all included studies. This was performed independently by two co-investigators (JK and MS), and any discrepancies were reviewed by the senior investigator (EK). Tools for methodological quality were used to assess articles individually. The Newcastle-Ottawa Quality Assessment Scale (NOS) for cohort and case-control studies was used (20). This instrument comprises nine points that determine the selection, comparability, and exposure. In this meta-analysis, articles were considered to have a high methodologic quality if they scored between 7-9; moderate-quality between 4-6; and low quality less than 4. Investigators were also asked to independently assess the overall relevance and overall validity of the included studies. Each of these categories was ranked as either high, moderate, or low.

\section{Statistical analysis}

Data were analyzed using Comprehensive Meta-Analysis version 3.0. For dichotomous scales, the effect size was pooled by Mantel-Haenszel (M-H) test and expressed as odds ratio (OR) along with a $95 \%$ confidence interval $(95 \%$ CI). Heterogeneity was assessed by Cochran's Q test and its magnitude defined by $\mathrm{I}^{2}$ statistic. In the case of significant heterogeneity, a random-effects model was applied, and potential clinical and methodological differences between studies were examined. Sensitivity analysis was performed by removing individual studies and rechecking heterogeneity.

\section{Results}

\section{Characteristics of included studies}

A PRISMA flow chart for the selection of articles in this study can be found in Figure 1. The initial literature search returned 23,770 records. After removal of duplicates and application of inclusion criteria, 27 unique full-text 

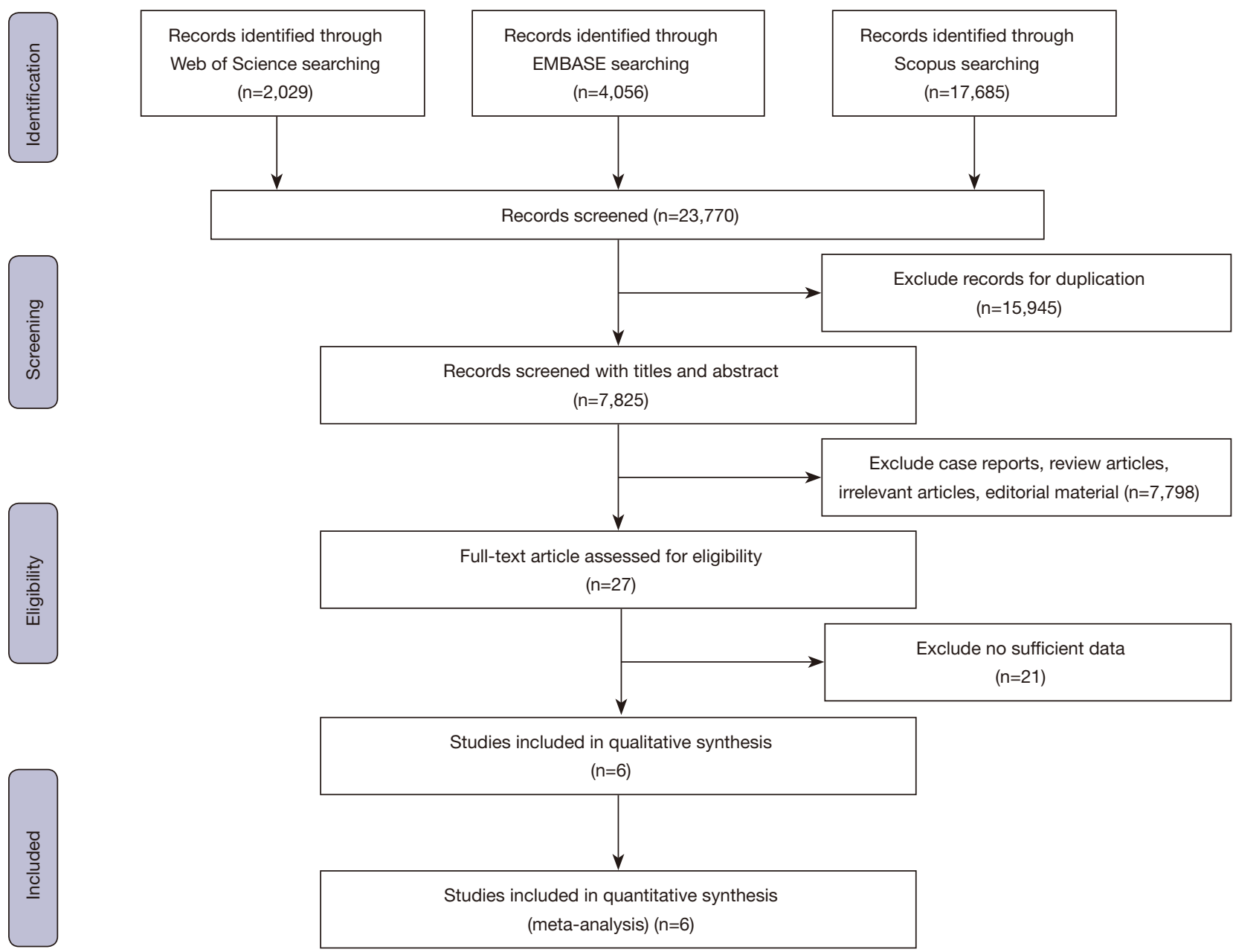

Figure 1 The workflow of literature search and study selection process.

Table 3 Characteristics of the selected studies

\begin{tabular}{|c|c|c|c|c|c|c|c|c|}
\hline Authors (reference) & $\begin{array}{c}\text { Year of } \\
\text { publication }\end{array}$ & Study design & Population & $\begin{array}{l}\text { Sample } \\
\text { size (n) }\end{array}$ & Case (n) & Control (n) & $\begin{array}{l}\text { Female } \\
\text { case }(n)\end{array}$ & $\begin{array}{c}\text { Female } \\
\text { control (n) }\end{array}$ \\
\hline Vadiveloo (14) & 2018 & Retrospective cohort & Scottish & 1,417 & 116 & 1,301 & 93 & 926 \\
\hline Underbjerg (3) & 2014 & Retrospective cohort & Denmark & 2,752 & 688 & 2,064 & 603 & 1,816 \\
\hline Almquist (18) & 2018 & Retrospective cohort & Sweden & 4,899 & 246 & 4,653 & 210 & 3,861 \\
\hline
\end{tabular}


Table 4 Summary of quality assessment of cohort and case-control studies

\begin{tabular}{|c|c|c|c|c|c|c|c|}
\hline Authors (reference) & Overall relevance* & Follow-up length & NOS score & Overall validity $^{\&}$ & Selection & Comparability & Outcome \\
\hline Underbjerg (2) & $\mathrm{H}$ & $<25$ years & 8 & $\mathrm{H}$ & $\star \star \star \star$ & $\star \star$ & $\star \star$ \\
\hline Underbjerg (3) & $\mathrm{H}$ & $<24$ years & 8 & $\mathrm{H}$ & $\star \star \star \star$ & $\star \star$ & $\star \star$ \\
\hline Bergenfelz (15) & $\mathrm{H}$ & 4.5 years & 7 & M & $\star \star \star$ & $\star$ & $\star \star \star$ \\
\hline Almquist (18) & $\mathrm{H}$ & 4.4 years & 7 & L & $\star \star \star$ & $\star$ & $\star \star \star$ \\
\hline
\end{tabular}

*, author assessment of overall relevance to the study; ", Newcastle-Ottawa Scale score, maximum of 9 ; ${ }^{*}$, overall author assessment of validity. Graded high $(\mathrm{H})$, medium $(\mathrm{M})$, or low $(\mathrm{L})$. H, high; M, moderate; L, low.

Table 5 Effect of postsurgical chronic hypoparathyroidism on morbidity and mortality

\begin{tabular}{|c|c|c|c|c|c|c|c|c|c|c|}
\hline $\begin{array}{l}\text { Morbidity and } \\
\text { mortality }\end{array}$ & $\begin{array}{l}\text { No of } \\
\text { studies }\end{array}$ & \multicolumn{2}{|c|}{ Sample size } & \multicolumn{3}{|c|}{ Effect size } & \multicolumn{3}{|c|}{ Heterogeneity } & $\frac{\text { Variance }}{\mathrm{T}^{2}}$ \\
\hline Cardiac disease & 3 & 1,023 & 7,541 & 1.33 & $1.07,1.66$ & 0.011 & 1.89 & 0.38 & $0 \%$ & 0.000 \\
\hline Arrhythmia & 2 & 920 & 6,514 & 1.32 & $0.96,1.80$ & 0.08 & 0.56 & 0.45 & $0 \%$ & 0.00 \\
\hline Renal disease & 2 & 927 & 6,647 & 4.85 & $3.54,6.65$ & $<0.001$ & 0.09 & 0.76 & $0 \%$ & 0.00 \\
\hline Seizure & 3 & 947 & 3,381 & 1.99 & $1.35,2.92$ & $<0.001$ & 19.73 & $<0.001$ & $89.8 \%$ & 1.10 \\
\hline Mental health & 2 & 804 & 3,365 & 1.39 & $1.13,1.70$ & 0.002 & 0.25 & 0.61 & $0 \%$ & 0.00 \\
\hline Fracture & 3 & 1,027 & 7,625 & 0.95 & $0.75,1.19$ & 0.62 & 3.06 & 0.21 & $35 \%$ & 0.25 \\
\hline Malignancy & 2 & 918 & 6,453 & 0.95 & $0.71,1.28$ & 0.75 & 4.16 & 0.041 & $75.9 \%$ & 0.49 \\
\hline Mortality & 3 & 804 & 3,365 & 1.19 & $0.96,1.49$ & 0.11 & 4.86 & 0.08 & $58.8 \%$ & 0.27 \\
\hline
\end{tabular}

A comparison of failure rate relative to success rate was applied. Heterogeneity was significant if $\mathrm{P}$ value $<0.1$ or $\mathrm{I}^{2}>50 \%$. Cl, confidence interval; $Q$ statistic, a measure of weighted squared deviations that denotes the ratio of the observed variation to the within-study error; $\mathrm{I}^{2}$, the ratio of true heterogeneity to total observed variation; $\mathrm{T}^{2}$, Tau squared and it is referred to the extent of variation among the effects observed in different studies.

publications were assessed for full-text review. Articles were excluded for irrelevant topics, lack of relevant data, or excluded study design. Ultimately, six retrospective cohort studies with a total of 14,055 patients were included for systematic review and meta-analysis. Characteristics of the included studies are listed in Table 3. The six citations included 1,432 patients with postsurgical chronic HypoPT and 12,623 controls. Of these, females accounted for 1,203 cases and 10,423 controls.

\section{Quality assessment of reviewed studies}

All included studies were of a moderate to high methodological quality with a median NOS score of 7.5 [interquartile range (IQR) 7.0 to 8.25] (Table 4). Studies primarily included European populations from 2013-2019, specifically, Denmark (2), Sweden (2), Belgium (1), and United Kingdom (1). 


\section{Pooled analysis of demographic characteristics}

Pairwise comparison between cases and controls revealed no significant difference in age $(\mathrm{P}=0.41)$ or gender $(\mathrm{P}=0.07)$. Studies showed no evidence of heterogeneity for age $\left(\mathrm{I}^{2}=0 \%\right)$ or gender $\left(\mathrm{I}^{2}=28.9 \%\right)$.

\section{Pooled analysis for the effect of chronic hypoparathyroidism on morbidities}

Table 5 summarizes the pooled effect size of chronic HypoPT on the development of multiple morbidities and mortality.

\section{Cardiac morbidity}

"Cardiovascular disease" comprises ischemic heart disease and strokes. Patients with postsurgical chronic HypoPT were more likely to have cardiac morbidities $(\mathrm{OR}=1.33$, 95\% CI: 1.06 to $1.65, \mathrm{P}=0.011$ ) (Figure $2 A$ ). Overall, 124 out of 1023 postsurgical chronic HypoPT patients developed cardiac problems $(12.1 \%)$, double the rate of the control group $(521 / 7,541,6.9 \%)$. However, a pooled analysis showed no significant difference in the risk of developing cardiac arrhythmia (OR $=1.32,95 \% \mathrm{CI}: 0.96$ to 1.79, $\mathrm{P}=0.08$ ) (Figure 2B).

\section{Renal morbidity}

Pairwise comparison showed a fourfold higher likelihood of renal disease ( $\mathrm{OR}=4.85,95 \% \mathrm{CI}$ : 3.54 to $6.65, \mathrm{P}<0.001$ ) (Figure $2 C$ ) and threefold higher risk of developing renal stones (OR=3.17, 95\% CI: 1.55 to $6.52, \mathrm{P}=0.002$ ) (Figure 2D). The risk of renal disease was $10.5 \%(97 / 927)$ in postsurgical chronic HypoPT compared to 1.4\% (91/6,647) among controls. Similarly, 3.4\% (36/1,069) developed renal stones compared to $0.3 \%(23 / 6,604)$ in the control population.

\section{Neuropsychiatric morbidity}

"Mental health concerns" include psychosis, schizophrenia, depression, affective disorders, and anxiety. "Neurologic morbidities" describe seizure. Forty-nine out of 947 HypoPT patients $(5.2 \%)$ developed seizures $(\mathrm{OR}=1.99$, $95 \%$ CI: 1.35 to $2.92, \mathrm{P}<0.001)$ compared to the control group (145/338, 4.3\%) (Figure $3 A$ ). Postsurgical chronic HypoPT patients were also more likely to develop mental health disorders such as generalized anxiety or depression $(\mathrm{OR}=1.39,95 \%$ CI: 1.33 to $1.69, \mathrm{P}=0.002)$ (Figure $3 B)$.

\section{Immunologic and oncologic morbidity}

Pooled data showed no effect on immune status.
$10.8 \%(87 / 804)$ of patients with chronic HypoPT were hospitalized with infections such as pneumonia compared to $11.6 \%(390 / 3,365)$ in the control group (OR $=1.04,95 \%$ CI: 0.81 to $1.33, \mathrm{P}=0.77$ ) (Figure $4 A$ ). Data did not show any difference related to malignancy $(\mathrm{OR}=0.82,95 \% \mathrm{CI}$ : 0.663 to $1.025, \mathrm{P}=0.08$ ) (Figure $4 B$ ).

\section{Skeletal morbidity}

Analysis did not show increased risk of developing fracture ( $\mathrm{OR}=0.94$, 95\% CI: 0.75 to $1.18, \mathrm{P}=0.62$ ) with $11 \%$ $(113 / 1027)$ developing fractures in postsurgical chronic HypoPT patients (Figure 5 A).

\section{Ophthalmic morbidity}

Pooled data showed no increase in the risk of developing cataract in postsurgical chronic HypoPT patients (OR $=1.21,95 \%$ CI: 0.78 to $1.87, \mathrm{P}=0.39$ ) (Figure $5 B$ ).

\section{Pooled analysis for the effect of chronic HypoPT on mortality}

In terms of crude mortality rate, our study showed no significant difference between the two groups $(\mathrm{OR}=1.19$, 95\% CI: 0.96 to $1.49, \mathrm{P}=0.12$ ) (Figure 6).

\section{Heterogeneity assessment for morbidities and mortality}

As depicted in Table 5, there was homogeneity across the studies for all variables except seizure $\left(\mathrm{I}^{2}=89.8 \%\right)$, malignancy $\left(\mathrm{I}^{2}=75.9 \%\right)$, and mortality $\left(\mathrm{I}^{2}=58.8 \%\right)$.

\section{Discussion}

Chronic HypoPT increased the risk of developing comorbidities across multiple organ systems. The mechanisms causing these adverse effects are poorly understood; however, basic science studies have suggested that high calcium/phosphate products in tissues can lead to the formation of crystals that may deposit in different systems $(21,22)$. Another theory is that longterm hypocalcemia may indirectly damage various body systems through poorly understood cellular pathways (23). This meta-analysis showed an increased risk of developing cardiac diseases, renal diseases, renal stones, seizures, mental health disorders, and infections in patients with postsurgical chronic HypoPT, but there was no significant impact on cardiac arrhythmia, bony fractures, malignancy, cataracts, or mortality. 


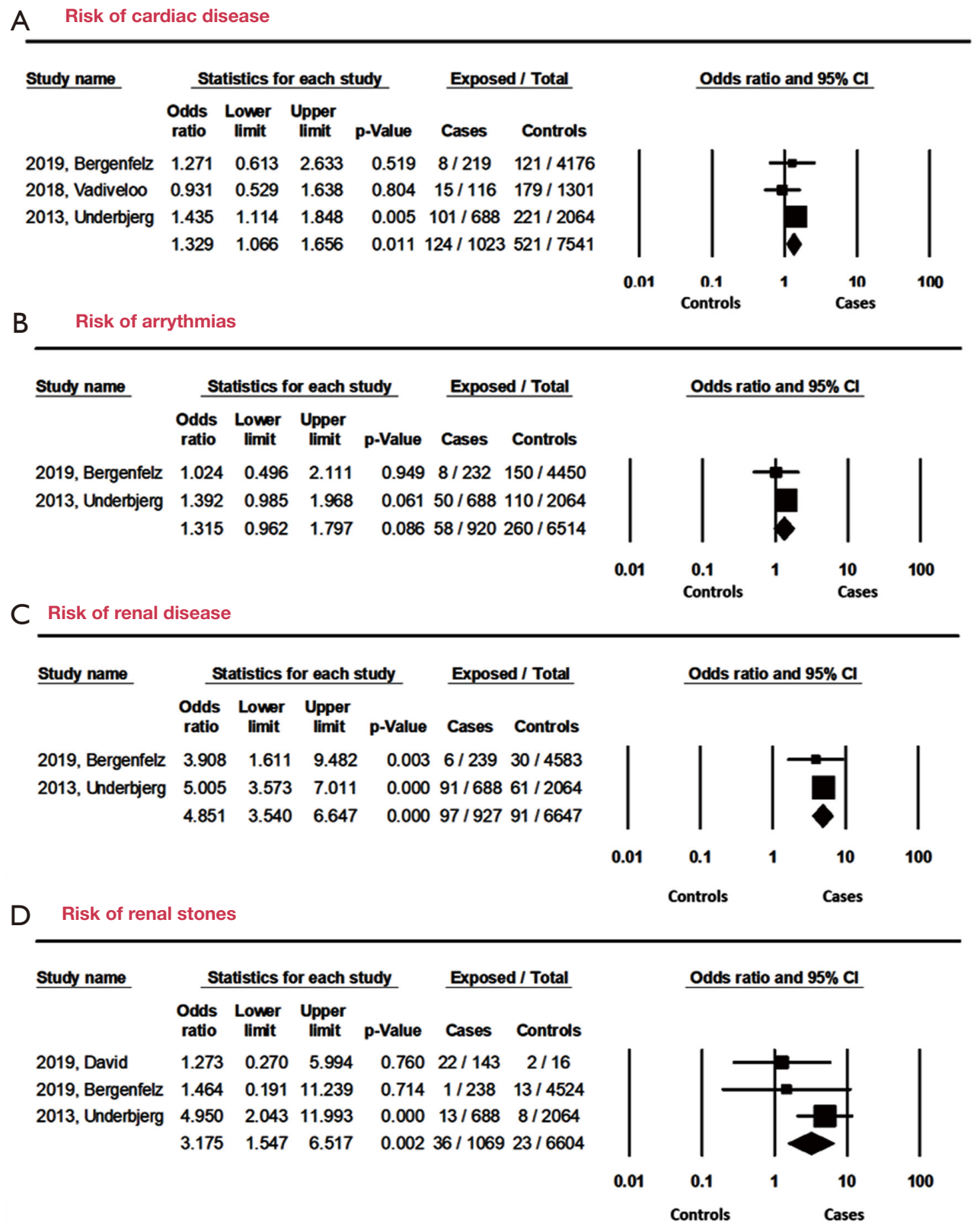

Figure 2 Forest plot presenting the effect of chronic HypoPT on cardiac and renal morbidities. (A) Cardiac disease; (B) developing arrhythmia; (C) renal disease; (D) renal stones. HypoPT, hypoparathyroidism.

Our study showed an increase in the risk of developing cardiovascular diseases (CVD) in postsurgical chronic HypoPT patients. Long-term hypocalcemia can lead to cardiomyopathy, long Q-T syndrome, arrhythmia, and increased levels of cardiac enzymes $(23,24)$. These results contradict other studies suggesting that postsurgical chronic HypoPT does not affect the cardiovascular system in patients without a previous history of CVD $(2,15,22)$. The same studies showed that chronic HypoPT increased the risk of cardiovascular events in patients with known underlying cardiovascular comorbidity prior to surgery $(15,22)$. This risk may increase by twofold or more on longterm follow-up (15). The risk of CVD was proven to be higher in non-surgical chronic HypoPT patients compared 


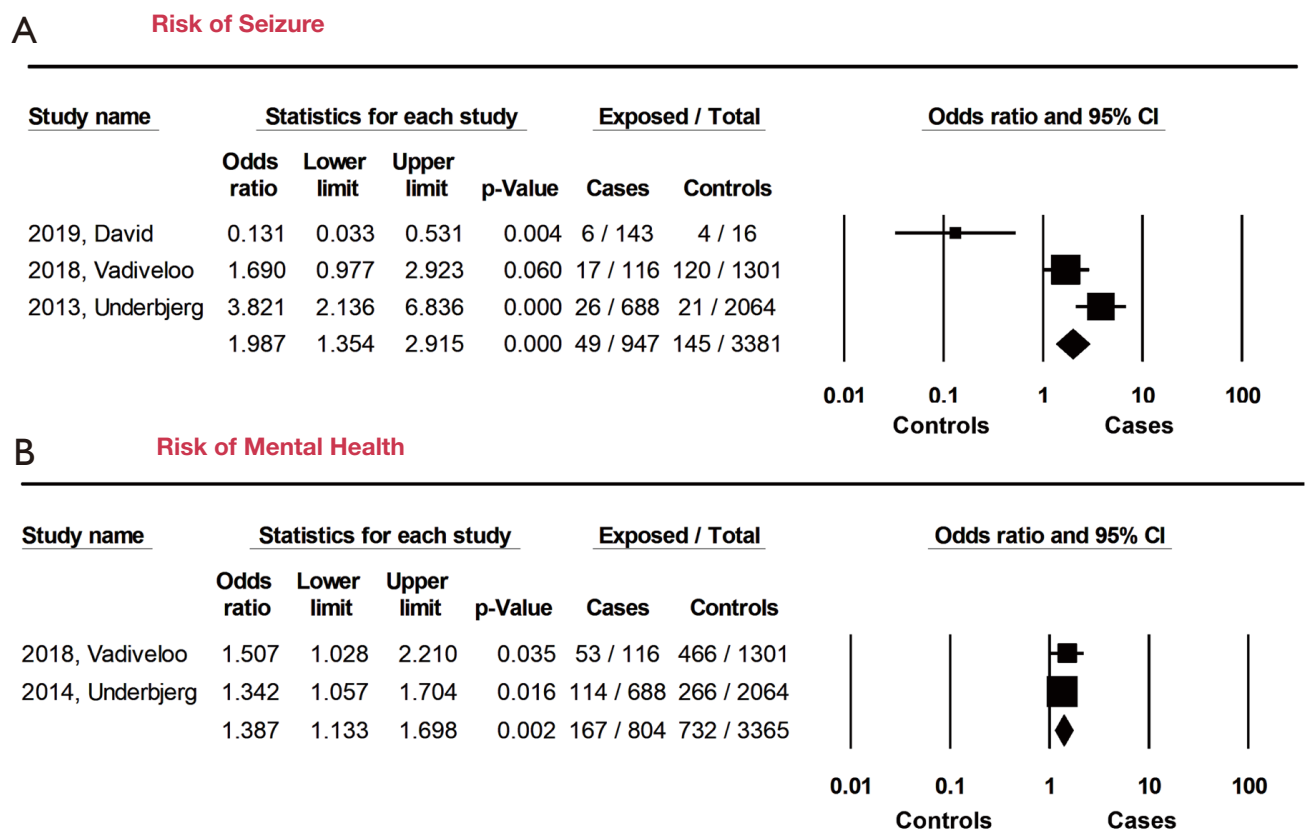

Figure 3 Forest plot presenting the effect of chronic HypoPT on neuropsychiatric morbidity: (A) seizure and (B) mental health. HypoPT, hypoparathyroidism.

A Risk of infection

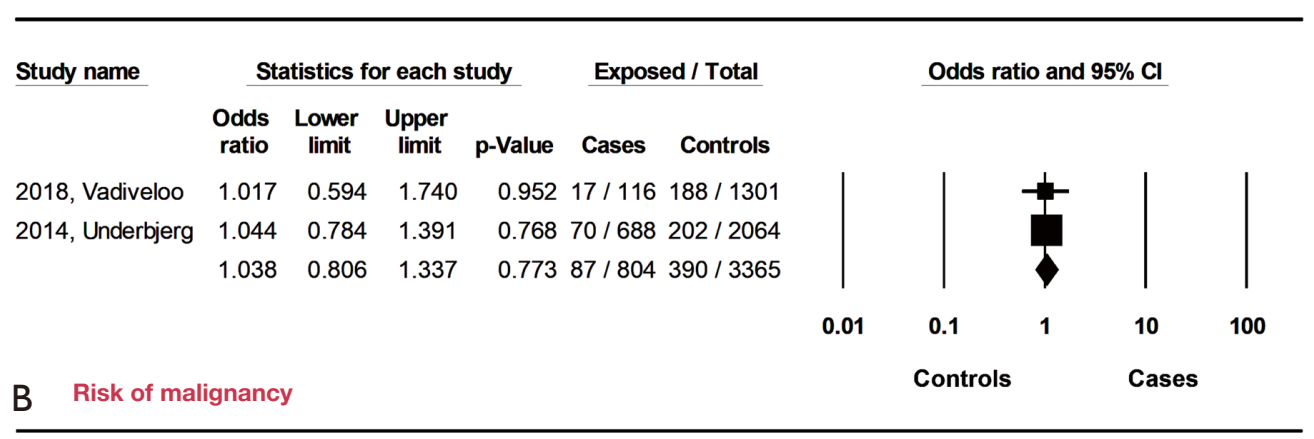

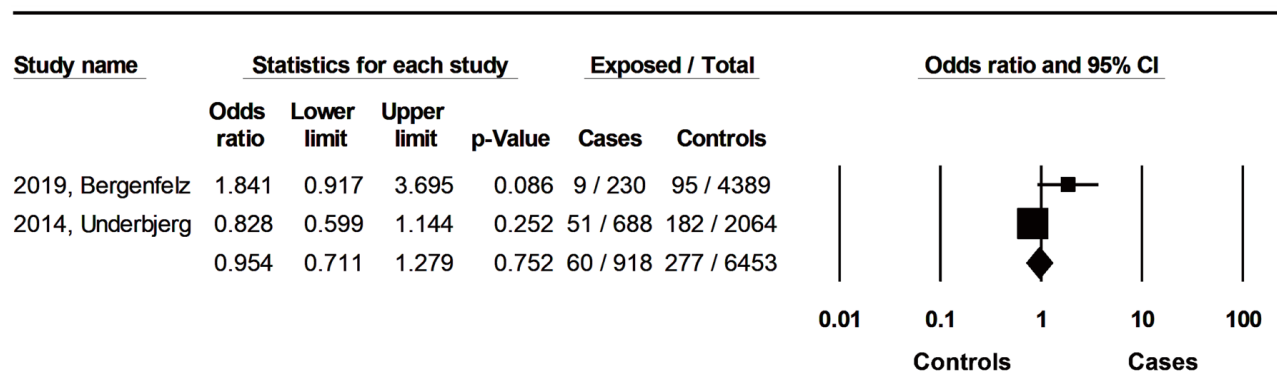

Figure 4 Forest plot presenting the effect of chronic HypoPT on immunologic and oncologic morbidity: (A) infection and (B) malignancy. HypoPT, hypoparathyroidism. 
A Risk of fracture

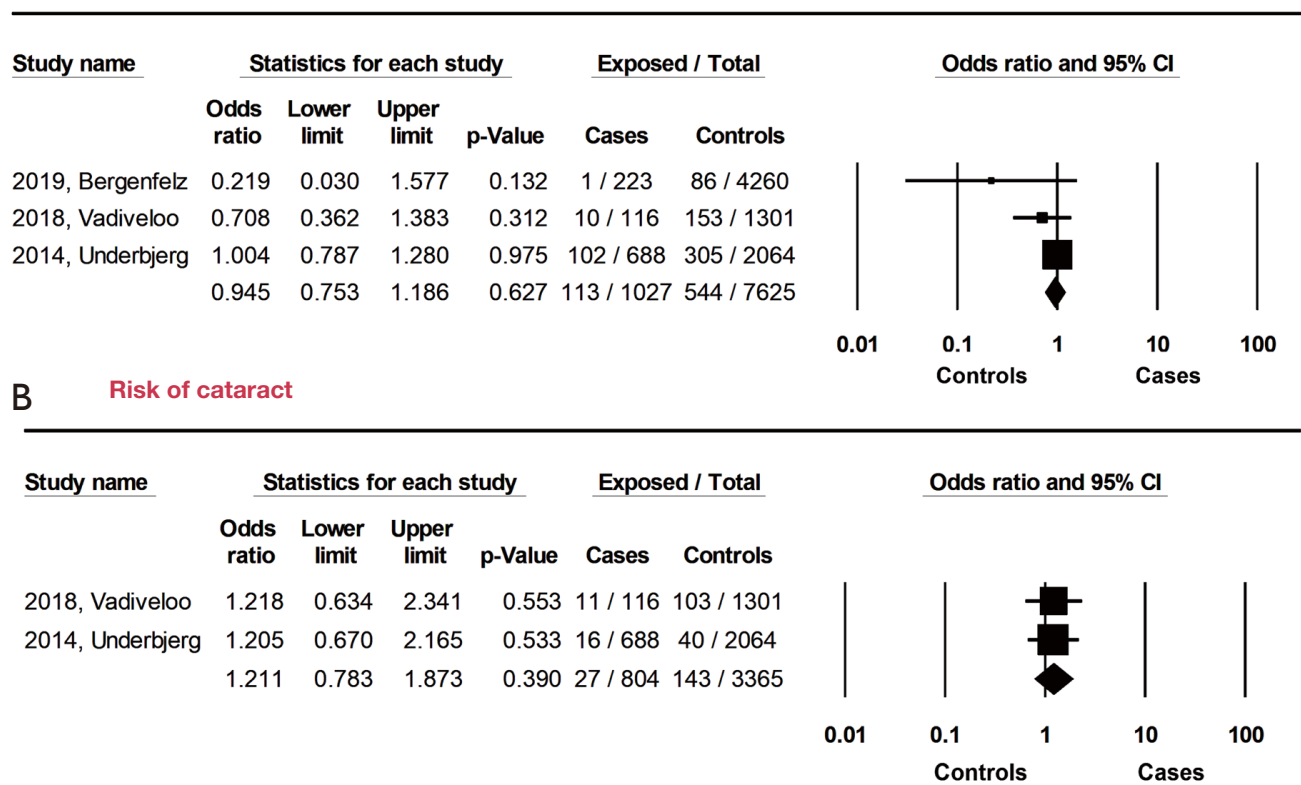

Figure 5 Forest plot presenting the effect of chronic HypoPT on skeletal and ophthalmological morbidities: (A) fracture, (B) cataract. HypoPT, hypoparathyroidism.

Risk of mortality

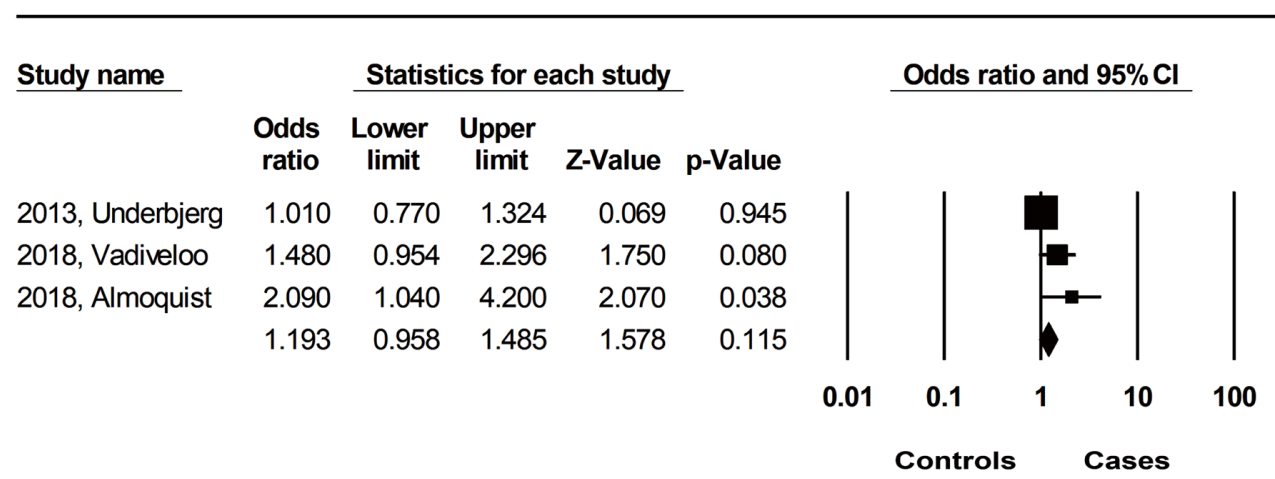

Figure 6 Forest plot presenting the effect of chronic HypoPT on the risk of mortality. HypoPT, hypoparathyroidism.

to postsurgical chronic HypoPT $(4,22)$.

Like CVD, postsurgical chronic HypoPT was shown to have a significant effect on the renal system. Bergenfelz et al. reported that permanent HypoPT increases the risk of renal insufficiency, which is consistent with the findings of Mitchell et al. $(15,25)$. The latter also reported an increased risk of renal calcifications and stones, which was supported by the cohort study conducted by David et al. $(17,25)$. Postsurgical chronic HypoPT patients are at five times higher risk of developing renal stones than the normal population (2,25). A positive correlation between high phosphate and calcium/phosphate levels and the increased risk of renal disease in general was reported (22). The risk of developing long-term renal morbidities is the same in postoperative HypoPT as in the non-surgical chronic HypoPT (4). Our meta-analysis supported the association between chronic HypoPT and developing renal morbidities.

Postsurgical chronic HypoPT has also been shown 
to increase the risk of seizure $(2,17,25)$. The mechanism underlying the development of seizure is not yet understood, but it could be due to the effect of intracellular calcium stabilizing cell membranes (14). David et al. and Mitchell et al. reported increased risk of seizure as high as $8.8 \%$, which was consistent with the findings of this metaanalysis $(9.9 \%)(17,25)$. Underbjerg et al. found that the risk of developing seizures could increase by fourfold compared to the normal population, and these episodes could carry debilitating consequences (2). The risk is the same in the non-surgical chronic HypoPT group (4).

Our meta-analysis, which included 1,027 patients who underwent neck surgeries and developed chronic HypoPT, showed no increased risk of developing bone fractures. This is supported by the findings in Danish and Scottish studies $(3,14)$. Underbjerg et al. reported a protective effect of chronic HypoPT against upper extremity fractures (3). Similarly, Bergenfelz et al. found the risk of fracture post-thyroidectomy to be $0.5 \%$ compared to $2 \%$ in the normal population (15). The same findings were reported by Underbjerg et al. for non-surgical patients with chronic HypoPT, except for the proximal humerus and forearm where the risk increased (4). Even so, this effect is poorly characterized and not well understood. Parathyroid hormone (PTH) plays an essential role in bone metabolism (26). Patients with chronic HypoPT often have a relatively low bone turnover status and high body mass index (27). This could explain the decreased risk of fracture in chronic HypoPT patients. In addition, the use of vitamin D supplements often affects muscle function and calcium resorption $(28,29)$.

It is well known that PTH also plays a regulatory role in the immune system; thus, a lack of PTH may impair the immune system and increase the risk of infection (30). Vitamin D also plays an important role in the regulation and expression of multiple genes responsible for activating the immune system $(31,32)$. Studies show that treating chronic HypoPT patients with a high dose of vitamin D can improve immunity and decrease the rate of infection (31-33). Phosphate hemostasis can also play a role in infection control (22). Studies showed that chronic HypoPT can increase the risk of infection by 1.4-2.0fold in both post-surgical and non-surgical groups compared to the normal population $(31,32)$. Underbjerg et al. showed that four or more hypocalcemic episodes increased the risk of infection by 2.7 -fold (22). The most common infection associated with chronic HypoPT was urinary tract infection (22). Median phosphate level above
$1.21 \mathrm{mmol} / \mathrm{L}$ was associated with an increase in the risk of upper respiratory tract infection but not urinary tract infection; moreover, disease duration increases the risk of infection (22). Underbjerg et al. reported that even after excluding urinary tract infection, the risk of other infections increased in patients with chronic HypoPT (22). This association was also observed for the risk of hospitalization secondary to infection. Results were not homogenous among the studies. Vadiveloo et al. did not report an increased risk of infection in their published series among surgical patients but reported a significant increase in the rate of infection in non-surgical chronic HypoPT patients (14). This is in contrast to our results, which showed an increased risk of infection as an effect in postsurgical chronic HypoPT.

Vitamin D receptors are found almost in every tissue type in the body (34-37). Several studies suggested that vitamin $\mathrm{D}$ can protect against gastrointestinal malignancies. Interestingly, some reports showed that chronic HypoPT could decrease the risk of gastrointestinal malignancies with increasing doses of calcium and vitamin $\mathrm{D}$ supplements (3,34-37). Bergenfelz et al. reported this finding, which showed an increased risk of malignancy in postsurgical chronic HypoPT patients compared to a population with normal parathyroid function. They did not reach definitive conclusions on causality but suggested that the finding could be due to chance, a causal relationship with hypoparathyroidism, medical treatment, or oversurveillance (15). Overall, the risk of malignancy was decreased in the non-surgical chronic HypoPT group per Underbjerg et al. (4). Our analysis could not find a relationship between postsurgical chronic HypoPT and developing cancers.

Our meta-analysis could not establish an association between postsurgical chronic HypoPT and the development of cataract. Chronic postsurgical HypoPT may lead to cataract due to calcium phosphate deposition in the lens (38). Our results are consistent with the results of Underbjerg et al. (3). Studies showed that HypoPT might increase the risk of mortality as well (22). However, our study could not establish a statistically significant increased risk of mortality among the postoperative chronic HypoPT patients. These results are consistent with Vadiveloo et al. (14).

\section{Limitations and future recommendations}

Our study has some limitations, including inevitable heterogeneity across studies in three variables reported, 
inconsistent follow-up period, and lack of information about the treatment protocol of vitamin D and calcium supplements. The limited geographical distribution (almost $80 \%$ of the postsurgical hypocalcemia cohort is from Northern Europe) is an important limitation to our study. Several factors can attribute to development of postsurgical hypocalcemia in Europeans including surgical techniques such as extensive dissection, limited sun exposure with higher prevalence of vitamin D deficiency. Studies investigating the complication of chronic post-surgical hypoparathyroidism among non-European populations should be conducted. Future studies from large databases (SEER, UKRETS, EUROCRINE) can investigate the impact on the postsurgical chronic HypoPT among North American population and help validate our study results. Due to the limited numbers of study published, an analysis comparing post-surgical chronic HypoPT vs. normal population with no hypoparathyroidism, then post-surgical chronic HypoPT vs. non-surgical chronic HypoPT could not be performed. Future studies and meta-analysis should estimate the risk of developing morbidities among these groups when enough studies are available in the literature.

Finally, due to the presence of few eligible studies, authors were not able to perform meta-regression analysis to test the magnitude of impact of study covariates.

\section{Implications on current clinical practice}

Given the higher risk of comorbidities in chronic postsurgical HypoPT patients, endocrinologist, family physicians, and primary care providers should give particular attention to this group of patients. Chronic postsurgical HypoPT patients should be educated about the symptoms of these sequalae especially ischemic heart diseases, stroke, and mental health diseases including anxiety and depression. Future studies may investigate if proper treatment of the chronic postsurgical HypoPT will normalize the risk.

\section{Conclusions}

To our knowledge, this is the first meta-analysis that reveals how postsurgical chronic HypoPT can increase the risk of morbidities. Our findings show chronic HypoPT to be associated with an increased risk of cardiac, renal, neurologic, immunologic, and psychiatric complications. Surgeons should be aware of the long-term development of such adverse events and use this knowledge when counseling patients preoperatively. Postoperative follow-up management and medical treatment administration should be strictly observed to avoid and manage such events.

\section{Acknowledgments}

Funding: None.

\section{Footnote}

Reporting Checklist: The authors have completed the PRISMA reporting checklist. Available at https://dx.doi. org/10.21037/gs-21-181

Peer Review File: Available at https://dx.doi.org/10.21037/ gs-21-181

Conflicts of Interest: All authors have completed the ICMJE uniform disclosure form (available at https://dx.doi. org/10.21037/gs-21-181). EK serves as an Editor-in-Chief of Gland Surgery. The other authors have no conflicts of interest to declare.

Ethical Statement: The authors are accountable for all aspects of the work in ensuring that questions related to the accuracy or integrity of any part of the work are appropriately investigated and resolved.

Open Access Statement: This is an Open Access article distributed in accordance with the Creative Commons Attribution-NonCommercial-NoDerivs 4.0 International License (CC BY-NC-ND 4.0), which permits the noncommercial replication and distribution of the article with the strict proviso that no changes or edits are made and the original work is properly cited (including links to both the formal publication through the relevant DOI and the license). See: https://creativecommons.org/licenses/by-nc-nd/4.0/.

\section{References}

1. Clarke BL, Leibson CL, Emerson JA, et al. Comorbid medical conditions associated with prevalent hypoparathyroidism: a population-based study. J Bone Miner Res 2011;26:S182.

2. Underbjerg L, Sikjaer T, Mosekilde L, et al. Cardiovascular and renal complications to postsurgical hypoparathyroidism: a Danish nationwide controlled historic follow-up study. J Bone Miner Res 2013;28:2277-85. 
3. Underbjerg L, Sikjaer T, Mosekilde L, et al. Postsurgical hypoparathyroidism--risk of fractures, psychiatric diseases, cancer, cataract, and infections. J Bone Miner Res 2014;29:2504-10.

4. Underbjerg L, Sikjaer T, Mosekilde L, et al. The Epidemiology of Nonsurgical Hypoparathyroidism in Denmark: A Nationwide Case Finding Study. J Bone Miner Res 2015;30:1738-44.

5. Vadiveloo T, Donnan PT, Leese GP. A PopulationBased Study of the Epidemiology of Chronic Hypoparathyroidism. J Bone Miner Res 2018;33:478-85.

6. Cipriani C, Pepe J, Biamonte F, et al. The Epidemiology of Hypoparathyroidism in Italy: An 8-Year Register-Based Study. Calcif Tissue Int 2017;100:278-85.

7. Cianferotti L, Parri S, Gronchi G, et al. Prevalence of Chronic Hypoparathyroidism in a Mediterranean Region as Estimated by the Analysis of Anonymous Healthcare Database. Calcif Tissue Int 2018;103:144-50.

8. Astor MC, Løvås K, Debowska A, et al. Epidemiology and Health-Related Quality of Life in Hypoparathyroidism in Norway. J Clin Endocrinol Metab 2016;101:3045-53.

9. Lorente-Poch L, Sancho JJ, Muñoz-Nova JL, et al. Defining the syndromes of parathyroid failure after total thyroidectomy. Gland Surg 2015;4:82-90.

10. Edafe O, Antakia R, Laskar N, et al. Systematic review and meta-analysis of predictors of post-thyroidectomy hypocalcaemia. Br J Surg 2014;101:307-20.

11. Asari R, Passler C, Kaczirek K, et al. Hypoparathyroidism after total thyroidectomy: a prospective study. Arch Surg 2008;143:132-7; discussion 138.

12. Almquist $M$, Hallgrimsson $P$, Nordenström E, et al. Prediction of permanent hypoparathyroidism after total thyroidectomy. World J Surg 2014;38:2613-20.

13. Chadwick DR. Hypocalcaemia and permanent hypoparathyroidism after total/bilateral thyroidectomy in the BAETS Registry. Gland Surg 2017;6:S69-74.

14. Vadiveloo T, Donnan PT, Leese CJ, et al. Increased mortality and morbidity in patients with chronic hypoparathyroidism: A population-based study. Clin Endocrinol (Oxf) 2019;90:285-92.

15. Bergenfelz A, Nordenström E, Almquist M. Morbidity in patients with permanent hypoparathyroidism after total thyroidectomy. Surgery 2020;167:124-8.

16. Clarke BL. Epidemiology and Complications of Hypoparathyroidism. Endocrinol Metab Clin North Am 2018;47:771-82.

17. David K, Moyson C, Vanderschueren D, et al. Long-term complications in patients with chronic hypoparathyroidism: a cross-sectional study. Eur J Endocrinol 2019;180:71-8.

18. Almquist M, Ivarsson K, Nordenström E, et al. Mortality in patients with permanent hypoparathyroidism after total thyroidectomy. Br J Surg 2018;105:1313-8.

19. Moher D, Liberati A, Tetzlaff J, et al. Preferred reporting items for systematic reviews and meta-analyses: the PRISMA statement. PLoS Med 2009;6:e1000097.

20. Stang A. Critical evaluation of the Newcastle-Ottawa scale for the assessment of the quality of nonrandomized studies in meta-analyses. Eur J Epidemiol 2010;25:603-5.

21. Blake J. Eye signs in idiopathic hypoparathyroidism. Trans Ophthalmol Soc U K 1976;96:448-51.

22. Underbjerg L, Sikjaer T, Rejnmark L. Long-Term Complications in Patients With Hypoparathyroidism Evaluated by Biochemical Findings: A Case-Control Study. J Bone Miner Res 2018;33:822-31.

23. Fisher NG, Armitage A, McGonigle RJ, et al. Hypocalcaemic Cardiomyopathy; the relationship between myocardial damage, left ventricular function, calcium and ECG changes in a patient with idiopathic hypocalcaemia. Eur J Heart Fail 2001;3:373-6.

24. Meyer T, Ruppert V, Karatolios K, et al. Hereditary long QT syndrome due to autoimmune hypoparathyroidism in autoimmune polyendocrinopathy-candidiasis-ectodermal dystrophy syndrome. J Electrocardiol 2007;40:504-9.

25. Mitchell DM, Regan S, Cooley MR, et al. Long-term follow-up of patients with hypoparathyroidism. J Clin Endocrinol Metab 2012;97:4507-14.

26. Poole KE, Reeve J. Parathyroid hormone - a bone anabolic and catabolic agent. Curr Opin Pharmacol 2005;5:612-7.

27. Sikjaer T, Rejnmark L, Thomsen JS, et al. Changes in 3-dimensional bone structure indices in hypoparathyroid patients treated with PTH(1-84): a randomized controlled study. J Bone Miner Res 2012;27:781-8.

28. Glerup H, Mikkelsen K, Poulsen L, et al. Hypovitaminosis D myopathy without biochemical signs of osteomalacic bone involvement. Calcif Tissue Int 2000;66:419-24.

29. Cranney A, Horsley T, O'Donnell S, et al. Effectiveness and safety of vitamin $\mathrm{D}$ in relation to bone health. Evid Rep Technol Assess (Full Rep) 2007;(158):1-235.

30. Geara AS, Castellanos MR, Bassil C, et al. Effects of parathyroid hormone on immune function. Clin Dev Immunol 2010;2010:418695.

31. Laaksi I, Ruohola JP, Mattila V, et al. Vitamin D supplementation for the prevention of acute respiratory tract infection: a randomized, double-blinded trial among young Finnish men. J Infect Dis 2010;202:809-14.

32. Murdoch DR, Slow S, Chambers ST, et al. Effect of 
vitamin D3 supplementation on upper respiratory tract infections in healthy adults: the VIDARIS randomized controlled trial. JAMA 2012;308:1333-9.

33. Murdoch DR, Slow S, Chambers ST, et al. Effect of vitamin D3 supplementation on upper respiratory tract infections in healthy adults: the VIDARIS randomized controlled trial. JAMA 2012;308:1333-9.

34. Garland C, Shekelle RB, Barrett-Connor E, et al. Dietary vitamin D and calcium and risk of colorectal cancer: a 19year prospective study in men. Lancet 1985;1:307-9.

35. Bostick RM, Potter JD, Sellers TA, et al. Relation of

Cite this article as: Hadedeya D, Kay J, Attia A, Omar M, Shalaby M, Youssef MR, Shama M, Toraih E, Kandil E. Effect of postsurgical chronic hypoparathyroidism on morbidity and mortality: a systematic review and meta-analysis. Gland Surg 2021;10(10):3007-3019. doi: 10.21037/gs-21-181 calcium, vitamin D, and dairy food intake to incidence of colon cancer among older women. The Iowa Women's Health Study. Am J Epidemiol 1993;137:1302-17.

36. Kearney J, Giovannucci E, Rimm EB, et al. Calcium, vitamin $\mathrm{D}$, and dairy foods and the occurrence of colon cancer in men. Am J Epidemiol 1996;143:907-17.

37. Kearney J, Giovannucci E, Rimm EB, et al. Calcium, vitamin $\mathrm{D}$, and dairy foods and the occurrence of colon cancer in men. Am J Epidemiol 1996;143:907-17.

38. Shoback D. Clinical practice. Hypoparathyroidism. N Engl J Med 2008;359:391-403. 